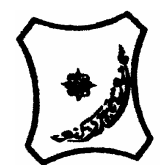

Bayero Journal of Pure and Applied Sciences, 3(2): 26 - 30

Received: May, 2010

Accepted: August, 2010

ISSN 2006 - 6996

\title{
SYNTHESIS AND CHARACTERISATION OF A WATER-SOLUBLE INITIATOR FOR ATOM TRANSFER RADICAL POLYMERISATION
}

Haruna Musa

Department of Pure and Industrial Chemistry, Bayero University Kano

\begin{abstract}
A water-soluble Atom transfer radical polymerisation (ATRP) initiator (1,2-dihydroxypropane-3oxy-2-bromo-2-methyl propionyl) has been synthesised by a two step reaction which involved esterification of the starting material and hydrolysis of the intermediate product. ${ }^{1} H$ NMR of both the intermediate and final products has confirmed the structure of the targeted products and also the reactions produce high yield and sufficient purity. This initiator will be very useful in the polymerisation of water-soluble monomers in order to produce polymers with controlled molecular weight and narrow polydispersity.
\end{abstract}

Keywords: Atom transfer, ATRP, Initiator, Polymerisation

\section{INTRODUCTION}

Free-radical polymerisation is the most important industrial process for producing various vinyl polymers. However, conventional free radical polymerisation techniques do not produce controlled molecular weights and molecular weight distributions due to large amount of chain transfer and termination reactions. In order to overcome these drawbacks, a new polymerisation technique known as Atom Transfer Radical Polymerisation (ATRP) was pioneered independently by (Matyjaszewski and Wang, 1995) and (Sawamoto et al., 1995).

Since its inception, ATRP also known as transition metal mediated living radical polymerisation has proven to be robust for the design of polymers of complex architecture and precise molar mass. This type of polymerisation is inert to many functional groups present in monomers or solvents, tolerant to impurities present in solvents and monomers and also allows for the facile synthesis of many polymers of novel structure and topology (Haddleton et al., 2000).

\section{Mechanism of ATRP}

The general mechanism for transition metal-mediated ATRP involves the generation of radicals (active

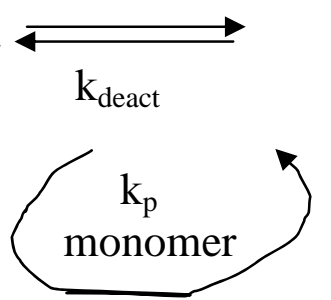

species) through a reversible redox process catalysed by a transition metal complex $\left(M_{t}{ }^{n}-Y /\right.$ Ligand, where $M_{t}$ is a transition metal having an oxidation number $n, Y$ may be another ligand or a counter ion) which undergoes a one electron oxidation with concomitant abstraction of a halogen atom (X) from an initiator (dormant species; R-X). This process occurs with a rate constant of activation $\left(\mathrm{k}_{\mathrm{act}}\right)$ and deactivation $\left(k_{\text {deact }}\right)$. Polymer chains grow by the addition of intermediate radicals to monomers in a similar manner to a conventional radical polymerisation, with the rate constant of propagation $\left(\mathrm{k}_{\mathrm{p}}\right)$. Termination reaction $\left(\mathrm{k}_{\mathrm{t}}\right)$ may also occur in ATRP but it's very negligible. This process generates oxidised metal complexes $\left(M_{t}^{n+1}\right)$ as persistent radicals to reduce the concentration of growing radicals thereby minimising termination reactions. The control of molar mass and of polydispersity in controlled radical polymerisation is achieved by converting the chain propagating radicals into a "dormant form" in equilibrium with the active form. This ensures a very low concentration of the active species and reduces termination reaction (Matyjaszewski and Xia, 2001).

$\mathrm{R}^{*}$

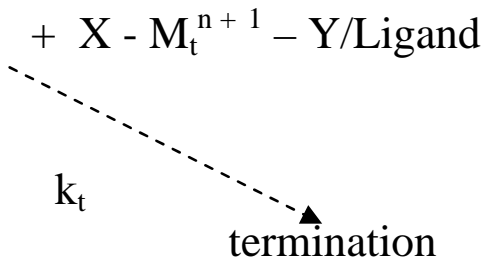

Figure 1: Mechanism of transition metal-mediated ATRP

\section{ATRP Initiators}

Like other polymerisation systems, ATRP is a multicomponent system which includes monomer, initiator, catalyst, solvent and temperature. Each of these components plays a significant role in ATRP hence careful choice of a suitable component is very essential for a successful ATRP.
Alkyl halides (RX) or their derivatives are mostly used as ATRP initiators and their main role is to determine the number of initiated chains. The polymerization rates in ATRP are first order with respect to the concentration of $\mathrm{RX}$ and the halide group (X) must rapidly and selectively migrate between the growing chain and the transition metal complex. 
Bromine and chlorine are the halogens that afford the best molecular weight control while iodine and fluorine do not work very well in ATRP due to very low C-I and very fast $\mathrm{C}-\mathrm{F}$ bond dissociation energies respectively (Patten and Matyjaszewski, 1998).

The choice of an ATRP initiator is a very important factor in a successful ATRP and also depends on the type of the polymer to be synthesised e.g. homopolymer, block copolymers or multi arm star polymers. Many researchers have demonstrated easier methods of preparation of ATRP initiators mostly by esterification of hydroxy-functional compounds with 2bromo-2-methylpropionyl bromide or its derivatives (Angot et al., 1998), (Vidts and Du-Prez, 2006), (Jankova et al., 1998).

\section{MATERIALS AND METHODS}

2,2-dimethyl-1,3-dioxolane-4-methanol (97\%, Acros), anhydrous tetrahydrofuran (Acros), Triethylamine (99.7\%, Acros), 2-bromo-2-methylpropionyl bromide (98\%, Acros), methoxybenzene (Acros). All other reagents and solvents were obtained at the highest purity available and used without further purification. All glassware was washed thoroughly, rinsed several times with de-ionised water and oven-dried overnight at $160^{\circ} \mathrm{C}$ prior to use.

\section{Synthesis of Water-Soluble Atrp Initiator}

The synthesis of the ATRP initiator (1,2dihydroxypropane-3-oxy-(2-bromo-2-methylpropionyl) was carried out in two steps as follows;

(i) Synthesis of 2,2-dimethyl-1,3-dioxolane-4methoxy-(2-bromo-2-methyl propionyl)

Triethylamine was dried over $\mathrm{KOH}$ pellets and glassware were dried overnight prior to use. 2,2dimethyl-1,3-dioxolane-4-methanol ( $0.04 \mathrm{~mol}, 5.29 \mathrm{~g})$, triethylamine $(0.08 \mathrm{~mol}, 8.10 \mathrm{~g})$ and anhydrous tertahydofuran $(50 \mathrm{ml})$ were charged in to a $100 \mathrm{ml}$ round-bottom flask equipped with a magnetic stirrer and cooled to $0^{\circ} \mathrm{C}$ with an ice bath.

2-bromo-2-methylpropionylbromide $(0.044 \mathrm{~mol}, 5.44$ $\mathrm{ml}$ ) was added drop wise via a syringe. The mixture was subsequently stirred for 45 minutes while being brought to ambient temperature. The reaction mixture was poured in to an excess of cold water and then extracted with $50 \mathrm{ml}$ of diethyl ether. The organic layer was separated, washed with a saturated solution of sodium carbonate, acidified water $(\mathrm{pH} \mathrm{4.5)}$ and a second aliquot of sodium carbonate. The organic layer was dried over anhydrous sodium sulphate, filtered and the solvent removed under vacuum.

2,2-dimethyl-1,3-dioxolane-4-methoxy-(2-bromo-2methylpropionyl) was finally isolated as a slightly yellowish oil. The product yield was $86 \%$.

$0.1 \mathrm{~g}$ of the oil was dissolved in equal amount of deuterated chloroform $\left(\mathrm{CDCl}_{3}\right)$ and the ${ }^{1} \mathrm{H}$ NMR was obtained using a JEOL DELTA-GX-270 MHz NMR spectrometer. The spectrum is presented in Figure 3.

(ii) Synthesis of 1,2-dihydroxypropane-3-oxy(2-bromo-2-methylpropionyl) (water-soluble ATRP initiator).

A mixture of $5 \mathrm{~g}$ of 2,2-dimethyl-1,3-dioxolane-4methoxy-(2-bromo-2-methyl propionyl), $15 \mathrm{ml}$ of glacial acetic acid, $40 \mathrm{ml}$ of water and 5 drops (catalytic amount) of methoxybenzene were stirred for 30 minutes at $80^{\circ} \mathrm{C}$ in a $250 \mathrm{ml}$ round-bottom flask. The solution was cooled to room temperature prior to the addition of $50 \mathrm{ml}$ of diethyl ether in a 1 litre separating funnel.

The crude product was obtained from the combined organic layers following the removal of solvent under vacuum. The crude product (yellowish oil) crystallises overnight on standing at ambient temperature and yields a yellowish solid that weighed $3.54 \mathrm{~g}$. The product was further recrystallised from $90 \mathrm{ml}$ of toluene and crystals were obtained. The percentage yield was $70 \% .0 .1 \mathrm{~g}$ of the product was dissolved equal amount of deuterated chloroform $\left(\mathrm{CDCl}_{3}\right)$ and the ${ }^{1} \mathrm{H}$ NMR was obtained using JEOL DELTA-GX-270 $\mathrm{MHz}$ NMR spectrophotometer. The spectrum is presented in Figure 5.

\section{RESULTS AND DISCUSSION}

The Synthesis of the ATRP initiator involved 2 steps. In the first step, high purity reagents and anhydrous solvents were used. This is necessary in order to avoid any unwanted side reactions normally caused by the presence of impurities e.g. water in the reaction medium.

Similarly, the acidic by-product $(\mathrm{HBr})$ produced in step 1 was neutralised with saturated solution of sodium carbonate until there was no effervescence, an indication of the complete neutralisation of the $\mathrm{HBr}$ by-product. The high percentage yield $(86 \%)$ obtained indicated the effectiveness of this method. The chemical equation involved in the formation of intermediate product (2,2-dimethyl-1,3-dioxolane-4methoxy-(2-bromo-2-methyl propio-nyl) is as follows; 


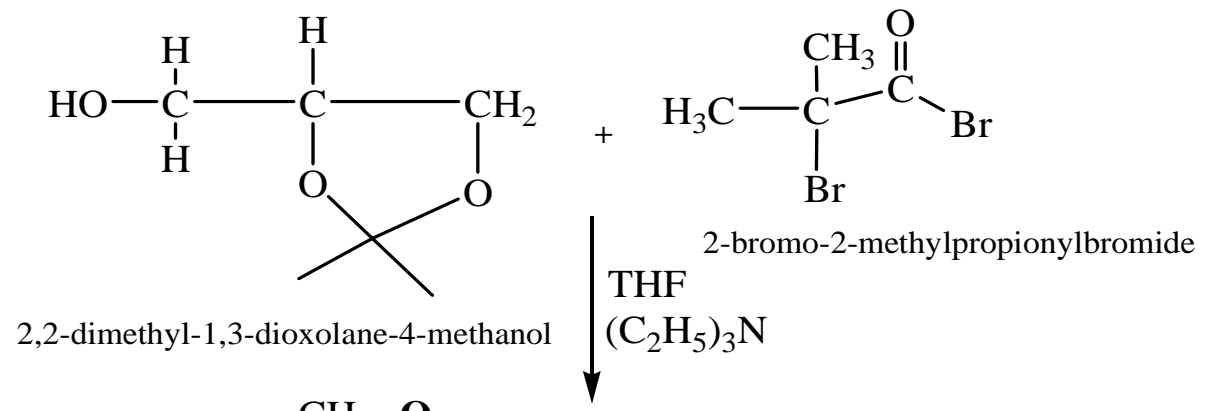<smiles>CC1(C)OCC(COC(=O)C(C)(C)Br)O1</smiles>

2,2-dimethyl-1,3-dioxolane-4-methoxy-(2-bromo-2-methylpropionyl)

Figure 2: Reaction scheme for the synthesis of intermediate for ATRP initiator.

Similarly, ${ }^{1} \mathrm{H}$ NMR of this intermediate product confirms the structure as shown in Figure 3

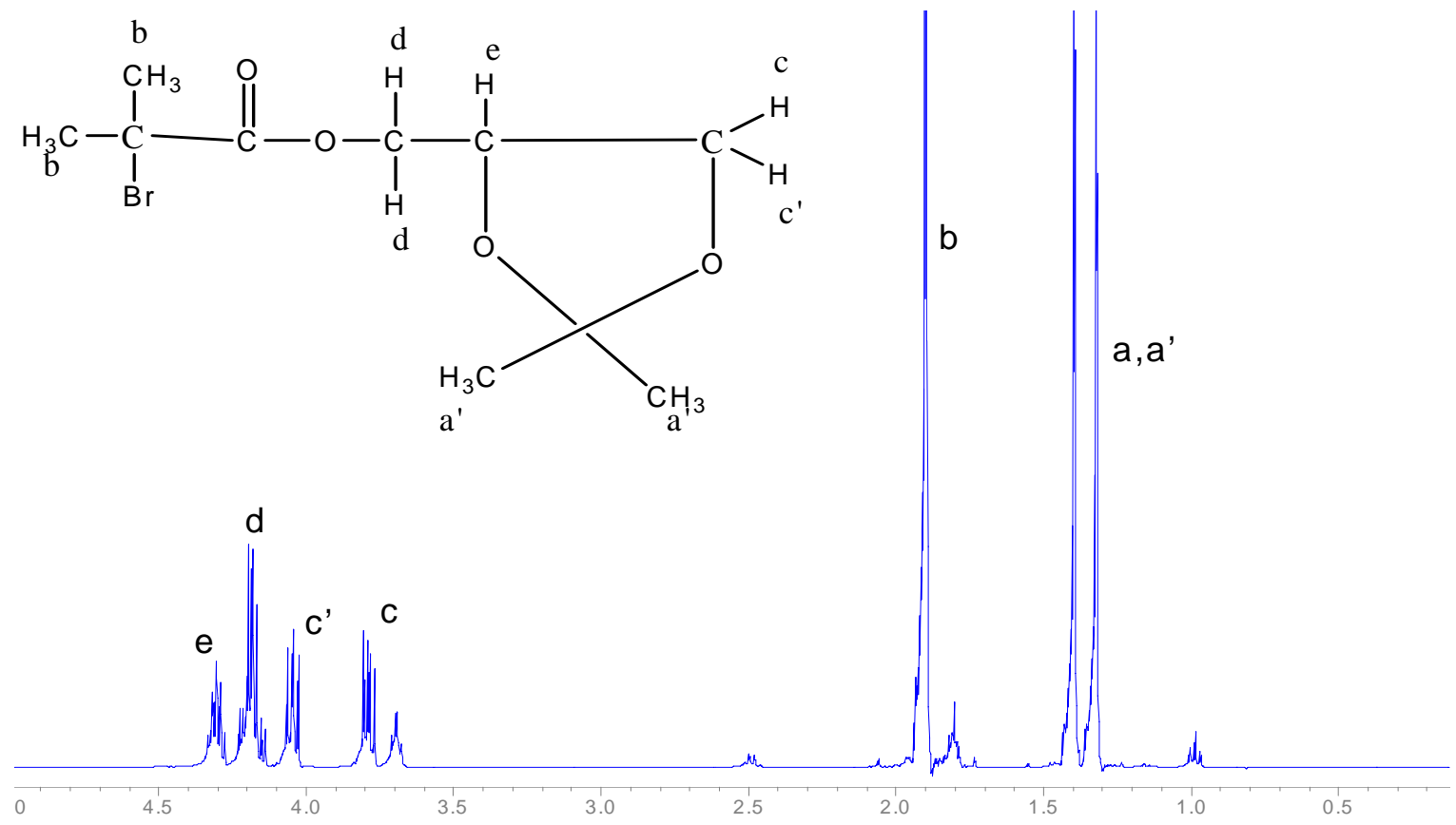

Figure 3: ${ }^{1} \mathrm{H}$ NMR of 2,2'-dimethyl-1,3-dioxolane-4-methoxy-(2-bromo-2-methylpropionyl) in Deuterated dimethyl sulfoxide (DMSO-d6), $\delta \mathrm{ppm:} 1.31$ and $1.38\left[\mathrm{~s}, 3 \mathrm{H}, \mathrm{OC}\left(\mathrm{CH}_{3}\right)_{2} \mathrm{O}\right], 1.93[\mathrm{~s}, 6 \mathrm{H}$, $\left.\mathrm{C}\left(\mathrm{CH}_{3}\right)_{2} \mathrm{Br}\right], 3.76(\mathrm{dd}, 1 \mathrm{H}, \mathrm{CHCHO}), 4.07$ (dd, $\left.1 \mathrm{H}, \mathrm{CHOCH}_{3}\right), 4.18-4.22\left(\mathrm{dd}, 2 \mathrm{H}, \mathrm{CH}_{2} \mathrm{OCO}\right), 4.31(\mathrm{~m}$, $1 \mathrm{H}, \mathrm{CHCH}_{2} \mathrm{O}$ ).

In the 2nd step, the product above was hydrolysed in acidic medium using methoxybenzene (anisole) as catalyst to produce the water soluble ATRP initiator (1,2-dihydroxypropane-3-oxy-2-bromo-2methylpropionyl) as follows; 
<smiles>CC1(C)OCCO1</smiles>

2,2-dimethyl-1,3-dioxolane-4-methoxy(2-bromo-2-methylpropionyl) $\stackrel{\text { (i) } \mathrm{CH}_{3} \mathrm{COOH}}{\longrightarrow}$<smiles>CC(C)(Br)C(=O)OCC(O)CO</smiles>

1,2-dihydroxypropane-3-oxy-2-bromo-2methylpropionyl) (ATRP initiator)

Figure 4: Reaction scheme for the synthesis of water-soluble ATRP initiator (1,2-dihydroxy propane-3-oxy-2-bromo-2methylpropionyl<smiles>[2H]C([2H])(O)C([2H])(O)C(C)OC(=O)C(C)(C)Br</smiles>

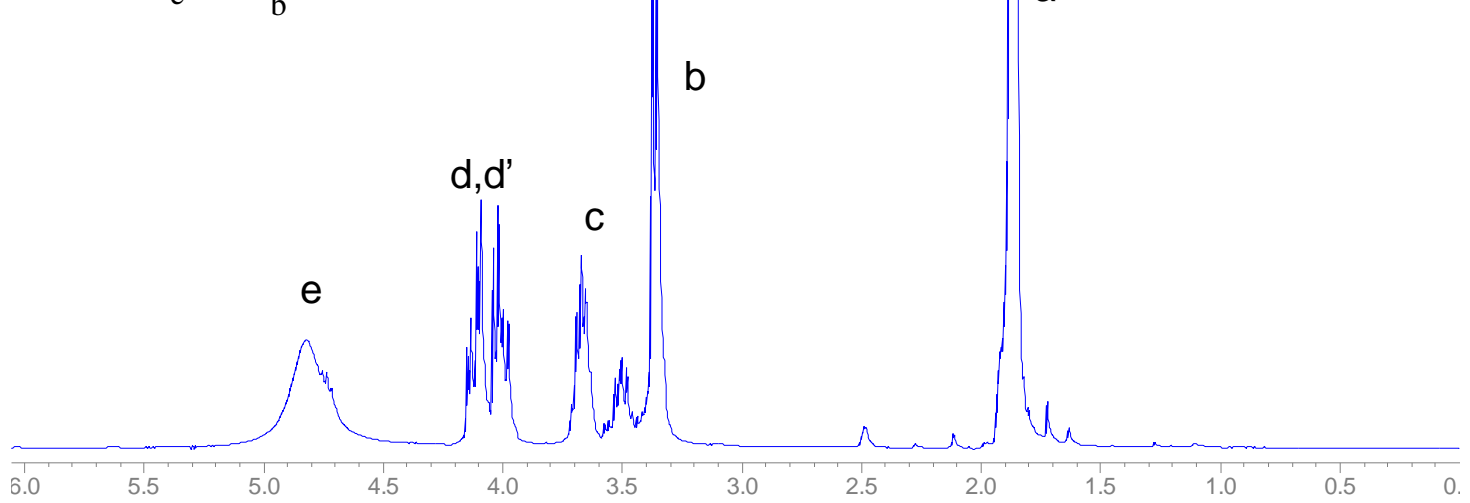

Figure 5: ${ }^{1} \mathrm{H}$ NMR of 1,2-dihydroxypropane-3-oxy-2-bromo-2methylpropionyl in Deuterated dimethyl sulfoxide (DMSO-d6), $\delta \mathrm{ppm:} 1.93\left[\mathrm{~s}, 6 \mathrm{H}, \mathrm{C}\left(\mathrm{CH}_{3}\right)_{2} \mathrm{Br}\right.$ ], $3.42\left(\mathrm{~d}, 2 \mathrm{H}, \mathrm{CH}_{2} \mathrm{OH}\right), 3.72(\mathrm{~m}, 1 \mathrm{H}$, $\mathrm{CHOH}$ ), 4.04 (dd, $\left.1 \mathrm{H}, \mathrm{CH}_{\mathrm{d}} \mathrm{OC}\right)$, 4.17 (dd, $\left.1 \mathrm{H}, \mathrm{CH}_{\mathrm{d}} \mathrm{OC}\right)$, 4.70- $4.90\left(\mathrm{~s}, 1 \mathrm{H},(\mathrm{OH})_{2}\right)$.

Similarly, ${ }^{1} \mathrm{H}$ NMR of the final product corresponds to the structure of the water-soluble ATRP initiator as shown in Figure 5. Further solubility test on this product confirm that it has an excellent solubility in water, hence it can be used as initiator in ATRP.

\section{CONCLUSION}

A water soluble ATRP initiator (1,2-dihydroxypropane3-oxy-2-bromo-2-methylpropionyl) has been synthesised by a two step reaction. ${ }^{1} \mathrm{H}$ NMR of both the intermediate and final products has confirmed the structure of the targeted products. In view of the current need of conducting polymerisation in water due to the fact that water is non-toxic, relatively cheaper and environmentally friendly, this initiator will be very useful in the polymerisation of water-soluble monomers in order to produce polymers with welldefined molecular weight and narrow polydispersity.

\section{Acknowledgement}

The Author thanks Bayero University Kano for Study Fellowship, Mac-Arthur Foundation \& Kano State Government for funding his PhD programme. 


\section{REFERENCES}

Angot, S., Murthy, S.K., Taton, D., and Gnanou, Y. (1998). Atom Transfer Radical

Polymerization of Styrene Using a Novel Octafunctional Initiator: Synthesis of WellDefined Polystyrene Stars, Macromolecules, 31, 7218-7225.

Haddleton, D. M.; Perrier, S.; Bon S. A. F. (2000), Copper(I)-Mediated Living Radical Polymerisation in the Presence of Oxyethylene Groups, Online $1 \mathrm{H}$ NMR Spectroscopy to Investigate Solvent Effects. Macromolecules, 33, 8246-8251.

Jankova, K.; Chen, X.; Kops, J.; Batsberg, W. (1998), Synthesis of Amphiphilic Polystyrene-bPoly(ethyleneglycol)-b-Polystyrene by Atom Transfer Radical Polymerisation, Macromolecules 31, 538-541.

Matyjaszewski, K., Wang, J. S. (1995), Controlled/"living" Radical Polymerisation. Atom Transfer Radical Polymerisation in the
Presence of Transition-Metal Complexes. /. Am. Chem. Soc., 117, 5614

Matyjaszewski, K.; Xia, J. (2001). Atom Transfer Radical Polymerisation. Chem. Rev., 101, 2921.

Patten, T. E.; Matyjaszewski, K. (1998), Atom Transfer Radical Polymerization and The Synthesis of Polymeric Materials, Adv. Mater. 10, 905

Sawamoto, M.; Kato, M.; Kamigaito, M.; Higashimura, T. (1995). Polymerisation of Methyl Methacrylate with the Carbon Tetrachloride/Dichlorotris(triphenylphoshine) ruthenium(II)/Methyl aluminium Bis(2,6ditert-butylphenoxide) Initiating System: Possibility of Living Radical Polymerisation. Macromolecules, 28, 1721.

Vidts, R.M.K. ; Du-Prez, F.E. (2006), Design of watersoluble block copolymers Containing 4vinylpyridine by ATRP. European Polymer Journal, 42, 43-50. 